\title{
Effects of Urban Street Spatial Parameters on Sound Propagation
}

\author{
Wu Hupeng ${ }^{1,2}$, Kang Jian ${ }^{1,2,3(*)}$, Jin Hong ${ }^{1,2}$ \\ 1. School of Architecture, Harbin Institute of Technology, Harbin 150001, China \\ 2. Heilongjiang Cold Region Architectural Science Key Laboratory, Harbin 150001, China \\ 3. School of Architecture, University of Sheffield, Sheffield S10 2TN, UK \\ * Corresponding author
}

\begin{abstract}
Many studies have demonstrated that the effect of urban street spatial shape on sound propagation cannot be ignored. Most previous studies are based on idealised spatial models and but not systematically and comprehensively examine the real and complex street space. This paper takes the actual streets of a high-density city as research objects, select reliable spatial parameters, obtain the acoustic propagation data using computer simulation, identify the sound propagation characteristics, and establish sound propagation models of urban streets. In total, 144 samples have been tested, 13 spatial parameters, including the width information, height information, section information and plan information of streets, have been selected, and three acoustic indices, which include the sound attenuation, reverberation time (RT30) and early decay time (EDT), have been analysed in this paper. The sound propagation in the urban street is consistent with the propagation characteristics of the semi-free sound field, i.e., the sound attenuation is linearly correlated with the logarithm of the sound propagation distance. This linear correlation becomes more pronounced for the greater Plan enclosure degree and more even distribution of façades. The trend of sound attenuations decreases with the increasing Cross-sectional enclosure degree, increasing Plan enclosure degree in the Near Zone or decreasing Vehicle lane width. RT30 is primarily distributed between $1.0 \mathrm{~s}$ and $3.0 \mathrm{~s}$ and tends to be stable when the propagation distance increases. The mean RT30 increases with the increasing Mean façade height, Sidewalk width, Cross-sectional enclosure degree in the Near Zone or Standard deviation of Plan enclosure degree in the Near Zone. The typical EDT distribution curve is clearly divided into two areas along the propagation direction. In the first area, the EDT value is notably small and nearly equals zero. With a sudden increase, the EDT maintains at a relatively stable value in the second area (stable area) of 0 to $3.0 \mathrm{~s}$. The mean EDT in the stable area increases with the increasing Vehicle lane width, increasing Cross-sectional enclosure degree or decreasing Standard deviation of Plan enclosure degree in the Near Zone.
\end{abstract}

Keywords: Urban Street, Spatial Parameter, Sound Propagation, Prediction Model

Date Received: 1 December 2016

Date Accepted: 17 May 2017

Publish online: 14 June 2017 


\section{Introduction}

People living in high-density cities suffer from both short- and long-term exposure to traffic noise pollution (Barceló et al., 2016). The studies of sound propagation in streets of high-density cities help to improve the sound environment. Numerous studies show that the streets in high-density cities, as a type of canyon-shaped space, have special sound propagation characteristics, and the effect of the urban street spatial shape on sound propagation cannot be ignored.

Picaut and Simon (2001) studied the sound propagation in 1:50 street scale model experiments with a $12 \mathrm{~m}$ height and variable width. Kang (2001) studied the sound propagation in the spatial form of street intersection with a $20 \mathrm{~m}$ height, and widths of 10 $\mathrm{m}, 20 \mathrm{~m}$ and $40 \mathrm{~m}$. Picaut et al. (2005) performed an experimental study of $50 \mathrm{~m}$ long sound propagation in a street with an $18 \mathrm{~m}$ height and $7.9 \mathrm{~m}$ width. Onaga and Rindel (2007) examined the effect of the scattering coefficient on the sound propagation in urban streets with a $20 \mathrm{~m}$ width and three different heights. Jang et al. (2015) assessed the noise reduction effects of vegetated façades using a 1:10 street canyon scale model with $10 \mathrm{~m}$ height and a $10 \mathrm{~m}$ width. Echevarria Sanchez et al. (2016) found that the urban canyon shape had an important effect on the road traffic noise levels for directly exposed receivers with a 25.6 $\mathrm{m}$ height and a $25 \mathrm{~m}$ width. Other studies on urban street sound propagation have also been based on models with specific dimensions (Bullen and Fricke, 1976 ; Heutschi, 1995a ; Hothersall et al., 1996 ; Kang, 1996 ; 2000 ; Oldham and Radwan, 1994 ; Radwan and Oldham, 1987 ; Wiener et al., 1965). There is still a lack of studies with a full range of urban street widths and heights. Therefore, in this study, a large amount of street samples has been considered in a high-density city.

As two common street spatial parameters, street width and façade height have been widely used in previous studies on sound propagation in urban streets, along with some other spatial parameters. Lee and Davies (1975) studied the sound propagation effected from one or more street intersections. Heutschi (1995b) predicted the effect of different parameters on the propagation of sound in street canyons. The parameters are the street width, height of the building, source receiver distance, gap width and position. The comparison between the predictions and measurements in real situations showed a consistency. Kang et al. (2001) compared two types of typical street spaces between the UK and Hong Kong. The comparison shows that for both the UK and HK streets, the gaps between buildings can typically introduce 3 to $5 \mathrm{~dB}$ noise reduction. Lee and Kang (2015) introduced a new parameter of height-to-width ratio to study its effect on sound fields in urban streets. Although there is a variety of spatial parameters for sound propagation study, few of them can be used to describe actual streets because of the random building gaps and changing façade heights. Therefore, new spatial parameters must be introduced to describe the complex actual street spaces.

The aim of this study is therefore to explore prediction models of sound propagation for actual urban streets. As the independent variable of these prediction models, a series of spatial parameters are introduced to describe street spaces based on a large amount of actual streets in a high-density city. The distributions of three acoustic indices (sound attenuation, RT30 and EDT) are used as representative of sound propagation characteristics. 


\section{Materials and Methods}

\subsection{Street samples}

As a typical high-density city, Harbin is in the cold climate of northeast Heilongjiang Province, China (Pan et al., 2011). It is the political, economic, cultural and trade centre in Heilongjiang Province and an important historical and cultural city. As a city raised by the China-Eastern Railway, the construction of Harbin was comprehensively affected by various exotic cultures such as European, Jewish, Japanese, etc. and local traditional culture in the past hundred years. Thus, different urban region buildings in different historical periods are notably different, particularly in the road systems. Overall, the urban regions of Harbin can be divided into traditional and modern types (Liu, 2012). Formed in the early construction of the city and affected by the western urban planning concept, the road systems of the traditional regions consist of square grids and radiation components. Away from the traditional regions, the modern regions were constructed since the $1980 \mathrm{~s}$, and few are affected by the city history. It has a typical road system in Chinese modern cities (Liu and Li, 2010).

According to Sun (2005), Harbin has 1789 roads with a total length of $1362 \mathrm{~km}$. Among them, there are 8 expressways with a total length of $19.55 \mathrm{~km} ; 57$ arterial roads of $138.21 \mathrm{~km} ; 109$ secondary trunk roads of $157.24 \mathrm{~km} ; 1622$ branch roads of $883.43 \mathrm{~km}$. The widths of the arterial road, secondary trunk road and branch road are 45 to $55 \mathrm{~m}, 40$ to 50 $\mathrm{m}$ and 15 to $30 \mathrm{~m}$, respectively, corresponding to the street classification method (MOHURD and AQSIQ, 2011), for large cities with a population of over 2 million. In this study, all street types are considered, except expressways, due to its small percentage.

In this study, stratified sampling method is used to improve the representativeness of the samples (Hansen et al., 1953). Urban streets in Harbin are divided into three categories (subpopulation), and a systematic sampling is applied within each subpopulation. Figure 1(a) shows the distribution and statistics of all 144 samples.
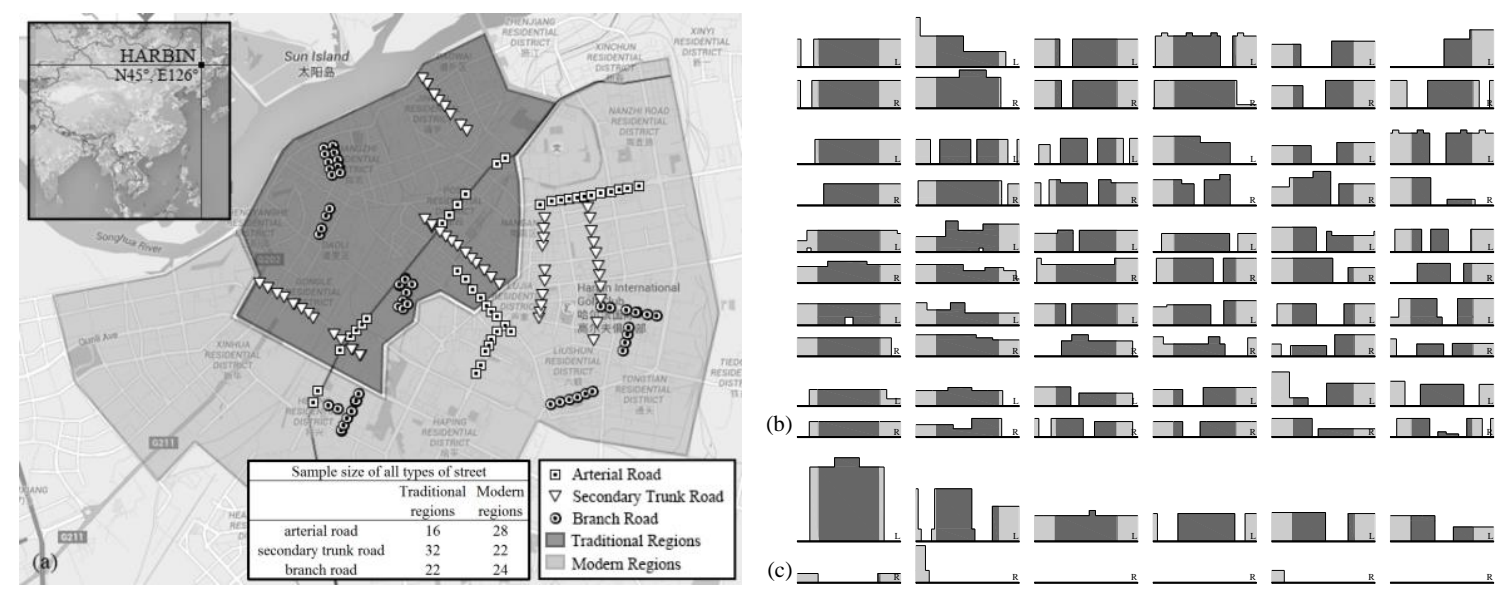

Figure 1 Urban street samples. (a) Distribution; (b) - (c) Typical samples.

\subsection{Street configurations for simulation}


Figure 2 shows the configurations of urban streets. Similar to previous studies (Lee and Kang, 2015 ; Onaga and Rindel, 2007), two 70-metre-long extra street spaces were added at both ends of the 60-metre-long measurement area to offset the effect of the ends on the measurement area. An omni-directional sound source was located on the vehicle lane that was $1 \mathrm{~m}$ high and $2 \mathrm{~m}$ away from the edge of the sidewalk. A series of receiving points were located in the both sidewalks, which had $2 \mathrm{~m}$ spacing and were $1.5 \mathrm{~m}$ high and $2 \mathrm{~m}$ from the vehicle lane edge. The results were averaged from two simulations, which were taken on both sides of the sample street, to avoid the effect of different street boundaries on the sound propagation.

In this model, the ground was defined as the solid asphalt concrete, so the absorption coefficient and scattering coefficient of the ground were 0.1 (Kang, 2000). All façades were defined as brick wall with plaster, so the absorption coefficient was 0.1(Kang, 2000), and the scattering coefficient was 0.3 (Lee and Kang, 2015). The effect of greening landscape and small structures on sound propagation was not considered.
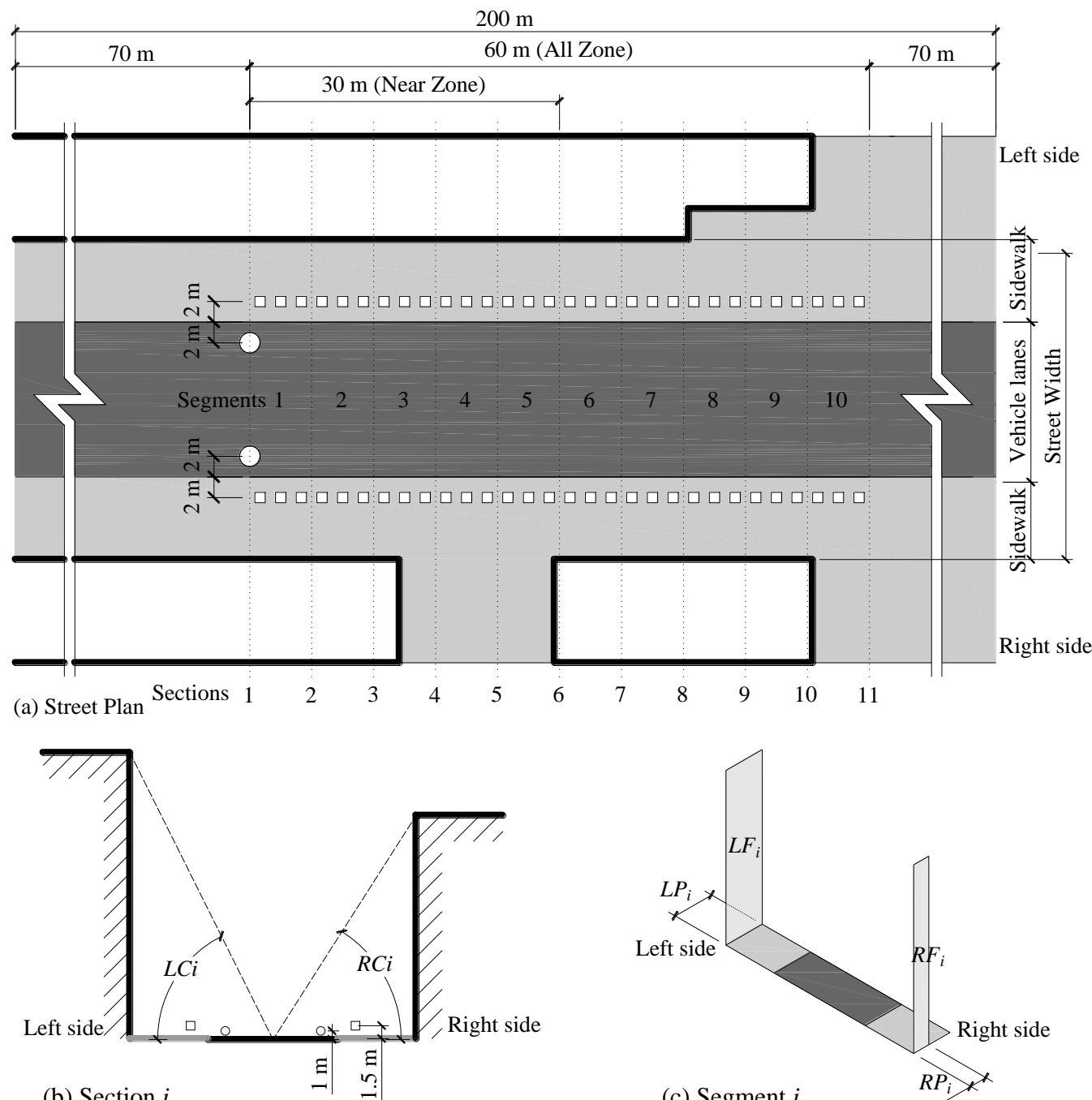

(b) Section $i$

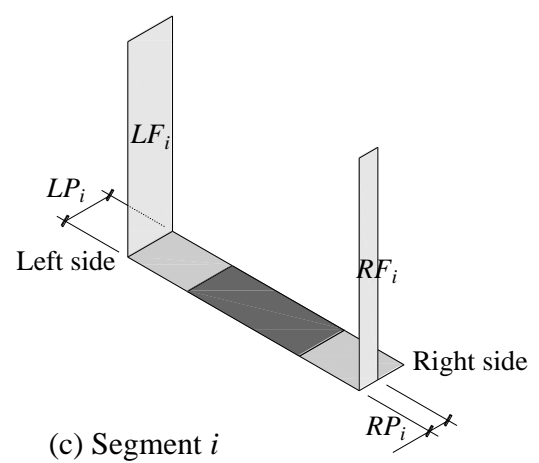

Figure 2 Streets Configurations and spatial parameters. 


\subsection{Spatial parameter}

Figure 1(b) - (c) shows 36 typical street samples. Unlike the ideal street models, the building heights of the actual streets change without rules. As shown in Figures 1(b), the samples in each row have similar building heights, but the size and location of the street façades are different. All samples in Figure 1(c) have buildings on only one side with different building heights. The ideal street spatial parameters such as building height and height-to-width ratio are not suitable to describe the real street. New parameters are required to study the sound propagation in the actual street space.

In the process of street sound propagation, façade reflection plays a vital role. According to the geometric reflection principle, the influence of façades in the range of about 0 to $30 \mathrm{~m}$ on the sound propagation is greater than that in the range of 0 to $60 \mathrm{~m}$. Therefore, street spatial parameters are extracted from these two zones, terms as Near Zone and All Zone, respectively, in this paper.

The street width (distance between the façades) is the most important spatial shape parameter in the study of urban street sound propagation because of the sound reflecting from the façades. However, streets with the same street width but different vehicle lane widths and sidewalk widths are quite common. Therefore, the street width $(W)$, vehicle lane width $\left(W_{\text {vehicle }}\right)$ and sidewalk width $\left(W_{\text {side }}\right)$ were selected to describe the width information of a street as shown in Figure 2.

The mean façade height $(H)$ was used to describe the façade height information because of the changing façade heights. However, as shown in Figure 1(b) - (c), the distribution of façade area in the measurement area is uneven. Therefore, the standard deviation of façade height $\left(\sigma\left(H_{A l l}\right)\right)$ was introduced to describe the degree of distribution of façade area in the measurement area. Figure 2 and Equations (1) - (4) show the calculate process of the mean façade height and standard deviation of façade height:

$$
\begin{aligned}
& H_{\text {Near }}=\frac{1}{5} \sum_{i=1}^{5} \frac{L F_{i}+R F_{i}}{6 \times 2} \\
& H_{A l l}=\frac{1}{10} \sum_{i=1}^{10} \frac{L F_{i}+R F_{i}}{6 \times 2} \\
& \sigma\left(H_{\text {Near }}\right)=\sqrt{\frac{1}{5} \sum_{i=1}^{5}\left(\frac{L F_{i}+R F_{i}}{6 \times 2}-H_{\text {Near }}\right)^{2}} \\
& \sigma\left(H_{\text {All }}\right)=\sqrt{\frac{1}{10} \sum_{i=1}^{10}\left(\frac{L F_{i}+R F_{i}}{6 \times 2}-H_{A l l}\right)^{2}}
\end{aligned}
$$

where $H_{\text {Near }}$ and $H_{A l l}$ are the mean façade heights of Near Zone and All Zone, respectively. $\sigma\left(H_{\text {Near }}\right)$ and $\sigma\left(H_{A l l}\right)$ are the standard deviations of façade height of Near Zone and All Zone, respectively; $L F_{i}$ and $R F_{i}$ are the façade areas on the left and right side, respectively, of section $i$.

The height-to-width ratio was also not suitable to describe the information of the street cross-section in real streets. Therefore, the cross-sectional enclosure degree was introduced. Figure 2 and Equations (5) - (6) show the calculate process of the crosssectional enclosure degree: 
$C_{\text {SNear }}=\frac{1}{6} \sum_{i=1}^{6}\left(\frac{L C_{i}+R C_{i}}{180}\right)$
$C_{\text {SAll }}=\frac{1}{11} \sum_{i=1}^{11}\left(\frac{L C_{i}+R C_{i}}{180}\right)$

where $C_{s N e a r}$ and $C_{s A l l}$ are the cross-sectional enclosure degree of Near Zone and All Zone, respectively; $a_{i}$ and $b_{i}$ are the angles formed by the midpoint of the street and both endpoints of the façade on the left and right sides, respectively, of section $i$.

An insightful study (Kang, 2002) found that a gap between buildings can provide approximately 2 to $3 \mathrm{~dB}$ extra sound attenuation, particularly in the vicinity of the gap. Therefore, the Plan enclosure degree and Standard deviation of Plan enclosure degree were introduced to describe the size and position of street gaps. Figure 2 and Equations (7) - (10) show the calculate process of the plan enclosure degree and standard deviation of plan enclosure degree:

$C_{\text {pNear }}=\frac{1}{5} \sum_{i=1}^{5}\left(\frac{L P_{i}+R P_{i}}{6 \times 2}\right)$

$C_{p A l l}=\frac{1}{10} \sum_{i=1}^{10}\left(\frac{L P_{i}+R P_{i}}{6 \times 2}\right)$

$\sigma\left(C_{\text {pNear }}\right)=\sqrt{\frac{1}{5} \sum_{i=1}^{5}\left(\frac{L P_{i}+R P_{i}}{6 \times 2}-C_{p N e a r}\right)^{2}}$

$\sigma\left(C_{p A l l}\right)=\sqrt{\frac{1}{10} \sum_{i=1}^{10}\left(\frac{L P_{i}+R P_{i}}{6 \times 2}-C_{p A l l}\right)^{2}}$

where $C_{p N e a r}$ and $C_{p A l l}$ are the Plan enclosure degrees of Near Zone and All Zone, respectively; $\sigma\left(C_{\text {pNear }}\right)$ and $\sigma\left(C_{p A l l}\right)$ are the standard deviations of Plan enclosure degree of Near Zone and All Zone, respectively; $L P_{i}$ and $R P_{i}$ are the façade widths on the left and right sides, respectively, of segment $i$.

Overall, different street spatial parameters indicate different spatial information. $W$, $W_{\text {vehicle }}$, and $W_{\text {side }}$ indicate the width information. $H_{\text {Near }}, H_{A l l}, \sigma\left(H_{N e a r}\right)$ and $\sigma\left(H_{A l l}\right)$ indicate the height information. $C_{s N e a r}$ and $C_{s A l l}$ indicate the section information. $C_{p N e a r}$, $C_{p A l l}, \sigma\left(C_{p N e a r}\right)$ and $\sigma\left(C_{p A l l}\right)$ indicate the ground plan information. Figure 3 describes the distributions of all spatial parameters. $W$ is mainly distributed between 15 to $70 \mathrm{~m}, W_{\text {side }}$ is mainly distributed between 4 to $20 \mathrm{~m}$, and $W_{\text {vehicle }}$ is evenly distributed between 8 to 40 m. The distributions of $H_{A l l}$ and $H_{\text {Near }}$ are similar, mainly between 10 to $30 \mathrm{~m}$. $\sigma\left(H_{N e a r}\right)$ is a little smaller than $\sigma\left(H_{A l l}\right)$ and both are distributed between 0 to $10 \mathrm{~m}$. Although $C_{p A l l}$ and $C_{\text {pNear }}$ are both mainly distributed between $70 \%$ to $100 \%$, the minimum of the former is $30 \%$ and that of the latter is $0 \%$. Except for some samples with a zero value, $\sigma\left(C_{p A l l}\right)$ and $\sigma\left(C_{p N e a r}\right)$ are mainly distributed between 1.5 to $3.5 \mathrm{~m} . \sigma\left(C_{p N e a r}\right)$ has more samples with a zero value than the other one. The distributions of $C_{s A l l}$ and $C_{\text {sNear }}$ generally show a similarity except for the range of $30 \%$ to $50 \%$. 

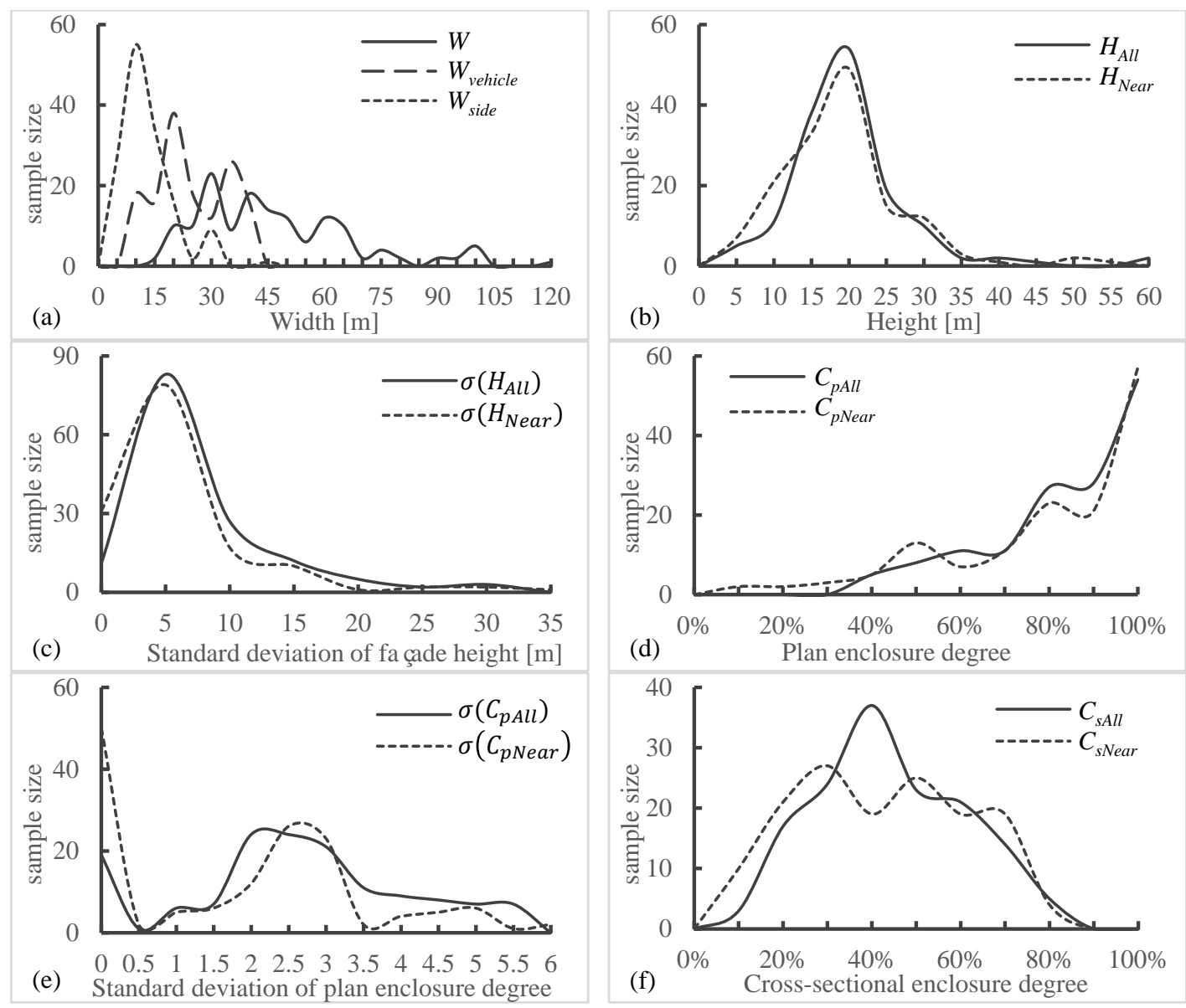

Figure 3 Distributions of all spatial parameters.

\subsection{Simulation methods}

The acoustics software package ODEON v9.0 was used to model typical urban streets. For point sources, a hybrid calculation method that combines the image source method for low-order reflections with a ray-tracing method for the late part of the response was used (Christensen, 2007). Lee and Kang (2015) verified a measurement study (Picaut et al., 2005) with the ODEON simulation and found that the differences between simulation and measurement were less than $15 \%$ in both sound pressure level and RT30. In addition, more studies on sound propagation of streets were based on Odeon (Ismail and Oldham, 2005 ; Jang et al., 2015 ; Kim et al., 2014). Therefore, in this paper, the effects of street space on sound propagation were investigated based on ODEON simulations.

ODEON simulations were performed by setting the transition order $(\mathrm{TO})=2$ using $1,000,000$ rays and a reflection order of 2000 . The impulse response length was fixed at $3000 \mathrm{~ms}$ throughout the simulation.

Sound decays due to the spreading of the wave, and sound scattering and absorption further weaken the sound. Reverberation time is the time taken for a sound to decay by 60 $\mathrm{dB}$ after an excitation stops. It is usually obtained by the $30 \mathrm{~dB}$ decay range, termed RT30, using linear regression techniques, when it is difficult to get a decay of $60 \mathrm{~dB}$. Early Decay 
Time (EDT) is derived from the decay curve using the section between $0 \mathrm{~dB}$ and $10 \mathrm{~dB}$ below the initial level. Ion this study, sound attenuation, RT30 and EDT were analysed, and all these three acoustic indices were widely used in studies (Kang, 2000 ; $2001 ; 2002$; Onaga and Rindel, 2007 ; Van Renterghem et al., 2006) that focused on sound propagation and sound environment in urban streets. Only the results at $1 \mathrm{kHz}$ are presented because the absorptions of the façades were uniform in the frequency range.

\subsection{Statistical methods}

The statistical analysis software SPSS v18.0 was used to analyse the results, which included Pearson correlation analysis (double) and linear stepwise regression analysis.

The Pearson correlation coefficient is a measure of the linear dependence (correlation) between two variables. The linear stepwise regression is a method of fitting regression models in which the choice of predictive variables is carried out by an automatic procedure (Efroymson, 1960 ; Hocking, 1976). In a regression analysis, the T value is used to determine the significance of the regression coefficients. Usually, it should be significantly greater than 2 (Schendera, 2014). The Durbin-Watson statistic is introduced in the linear regression models to detect the presence of autocorrelation (a relationship between values separated from each other by a given time lag) in the residuals (prediction errors) (Durbin and Watson, 1951). The variance inflation factor (VIF) quantifies the severity of multicollinearity in an ordinary least squares regression analysis. It provides an index that measures how much the variance (the square of the estimate's standard deviation) of an estimated regression coefficient is increased because of collinearity. Usually, if VIF > 10, then multicollinearity is high (Kutner et al., 2004).

\section{Results and Discussion}

\subsection{Difference between three street categories}

Figure 4 shows the distributions of the mean sound attenuation, RT30 and EDT in different street categories. As shown in Figure 4(a), the distribution patterns of the mean sound attenuation are similar in different street categories, that is, the sound attenuation is proportional to the logarithm of the sound propagation distance. The only difference is that the sound attenuation trend decreases with a lower road grade. The differences of sound attenuation between arterial road and branch road are $0.3 \mathrm{~dB}$ and $1.7 \mathrm{~dB}$ respectively at receiving point 1 and 30. As shown in Figure 4(b), the distribution patterns of the mean RT30 are also similar in different street categories, that is, after an increasing in the propagation distance from 0 to $10 \mathrm{~m}$, the mean RT30 maintains consistent in the last propagation distance. The only difference is that the mean RT30s of arterial road and branch road are almost the same, and the mean RT30s of secondary trunk road is $0.32 \mathrm{~s}$ less than that of others. Although the distribution patterns of the mean EDT are similar between secondary trunk road and branch road, the mean EDT of the branch road is slightly greater than that of the secondary trunk roads. The mean EDT of the arterial road is slightly less than that of others in the propagation distance from 0 to $30 \mathrm{~m}$ and much greater than others in the further propagation distance. 

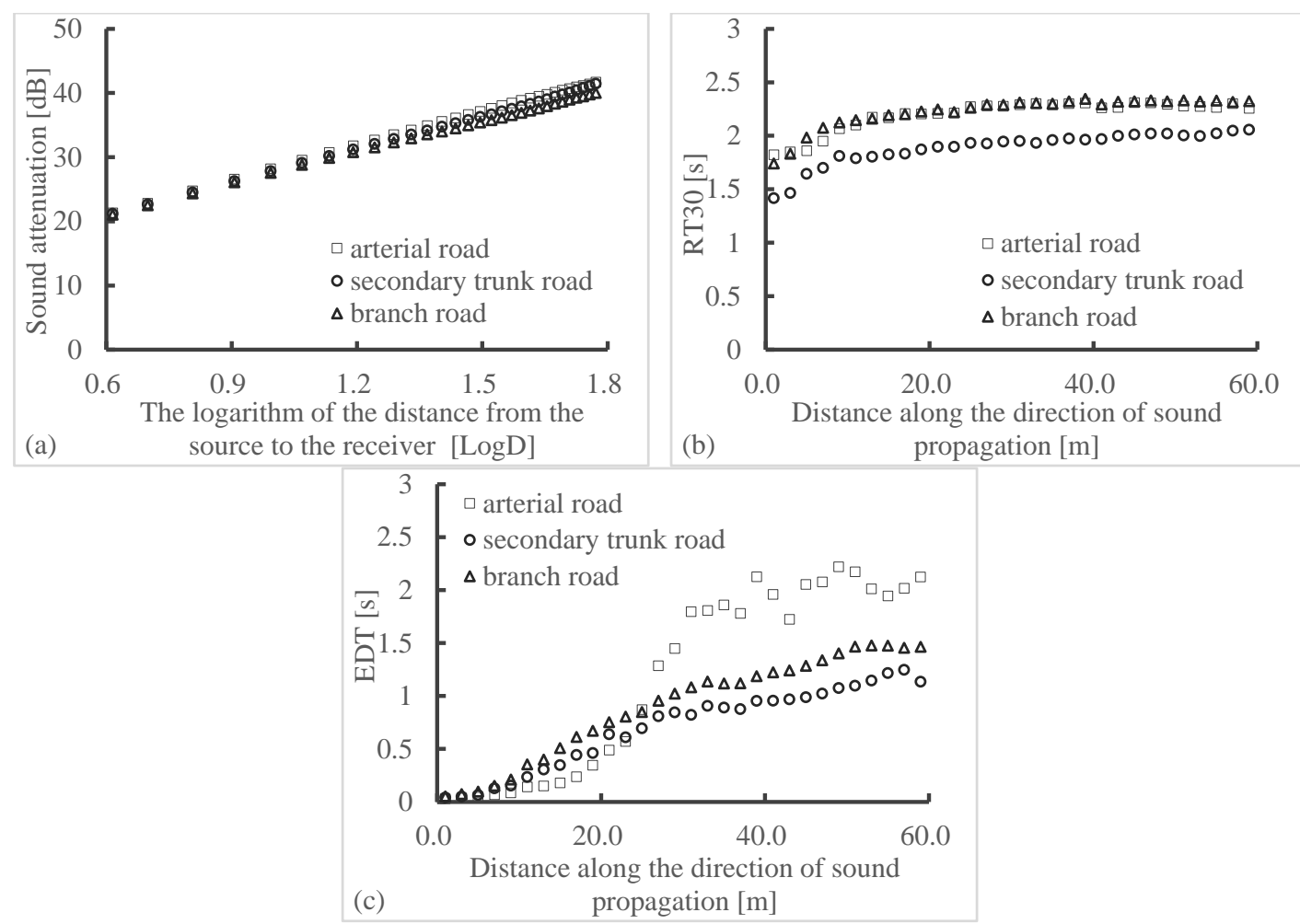

Figure 4 The distributions of mean sound attenuation, RT30 and EDT in different street categories. (a) Sound attenuation; (b) RT30; (c) EDT.

\subsection{Sound attenuation along the length}

\subsubsection{Basic features of sound attenuation}

Figure 5 depicts the distributions of sound attenuation along the direction of sound propagation. In Figure 5(a), a semi-free acoustic field curve and the sound attenuation of all samples along the streets are shown. Semi-free sound field is a sound field region with no adjacent reflecting surfaces expect ground. In practice a $6 \mathrm{~dB}$ increase in sound attenuation in the semi-free field when the distance doubles. As shown in Figure 5(a), the semi-free sound field curve is the boundary of all sound attenuation distributions. Hence, for broad streets, the values of sound attenuation are close to that of the semi-free field. For most streets, the values of sound attenuation are less than that of the semi-free field.

The extreme and mean values of sound attenuation are shown in Figure 5(b). The curves of linear regression correlations between the relative SPL and the logarithm of the distance from the source to the receivers are also plotted. When the distance doubles, the sound attenuations increases by 4.6 to $6.1 \mathrm{~dB}$, which is $5.1 \mathrm{~dB}$ on average. Therefore, without considering extreme cases, it can be considered that the sound propagation in the urban streets shows characteristics of a reverberation field, because the increasing of sound attenuation is less than $6 \mathrm{~dB}$ when the distance doubles. In addition, the differences between the maximum and minimum values increase with the increase in propagation 
distance. The differences are approximately $2 \mathrm{~dB}$ at the receiver position of $1 \mathrm{~m}$ and $7 \mathrm{~dB}$ at the receiver position of $59 \mathrm{~m}$ along the street for all samples.

Linear regression models were established for each sample with the logarithm of the distance from the source to the receivers as an independent variable and the sound attenuation as a dependent variable. The p-values of all linear regression models are 0.000 . The minimum of determination coefficient $R^{2}$ is 0.977 , and $70 \%$ of the $R^{2}$ values are more than 0.995. It demonstrates that the sound attenuation is proportional to the logarithm of the distance from the source to the receivers in the urban streets.
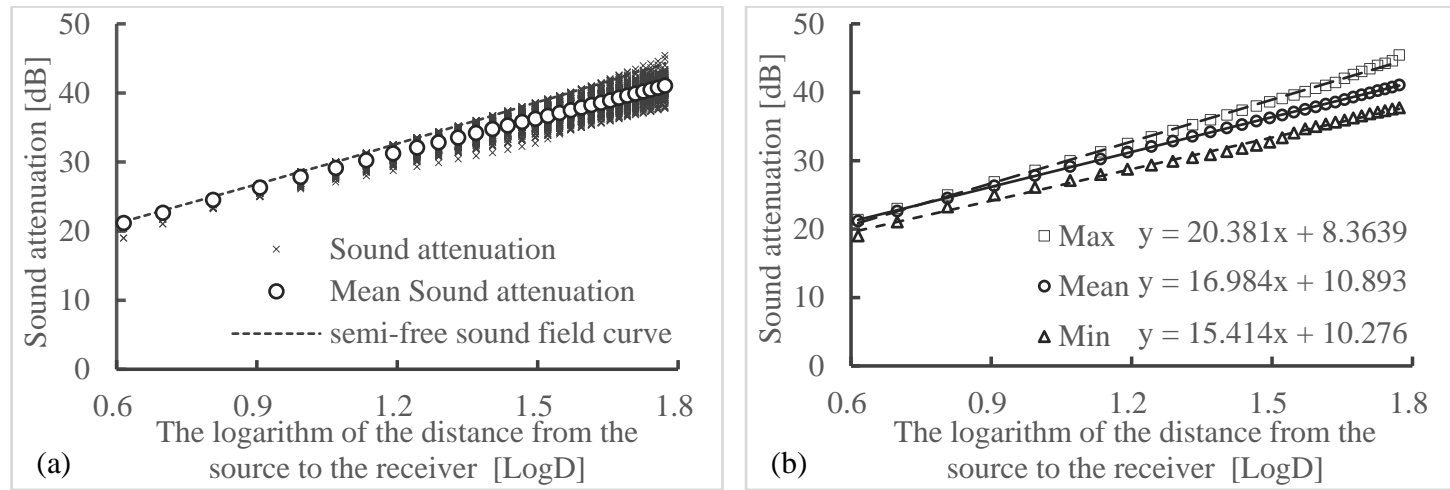

Figure 5 Sound attenuation distribution along the propagation directions. (a) Sound attenuation values; (b) Extreme and mean values of sound attenuation.

\subsubsection{Analysis of factors}

A better $\mathrm{R}^{2}$ of the regression model for the sound attenuation indicates that the prediction of the sound attenuation regression model is more accurate. Although $\mathrm{R}^{2}$ of the regression model for the sound attenuation was sufficiently large $\left(R_{M I N}^{2}=0.977, p=\right.$ $0.000)$, there is a difference of $R^{2}$ among different samples. The correlation analysis of the spatial parameters and $\mathrm{R}^{2}$ of the regression model is shown in Table 1. $C_{p}$ has a significant positive correlation with $\mathrm{R}^{2}$, whereas $\sigma\left(C_{p}\right)$ has a significant negative correlation with $\mathrm{R}^{2}$. The correlations of both $C_{p}$ and $\sigma\left(C_{p}\right)$ are stronger in the Near Zone $(30 \mathrm{~m})$ than in All Zone $(60 \mathrm{~m}) . H$ is weakly and positively correlated with $\mathrm{R}^{2}$, whereas $\sigma\left(H_{N e a r}\right)$ is weakly and negatively correlated with $\mathrm{R}^{2}$. Thus, higher $H$ corresponds to a smaller change in façade height in the Near Zone (smaller $\sigma\left(H_{N e a r}\right)$ ) and greater $\mathrm{R}^{2} . C_{s}$ has no significant correlation with $\mathrm{R}^{2}$.

The slope of the sound attenuation curve is a decisive parameter that reflects the characteristics of sound propagation. A smaller slope of the sound attenuation curve indicates less sound attenuation and a larger noise effect range. In total, 31 samples with $\mathrm{R}^{2}$ greater than 0.999 were selected to accurately find the factors of the slope. As shown in Table 1, there are certain linear correlations between most spatial parameters and the slope of the sound attenuation curve. It is notable that $C_{s}$ and $C_{p}$ have greater negative linear correlations with the slopes, and $W, W_{\text {vehicle }}$ and $W_{\text {side }}$ had greater positive linear correlations with the slopes than the other spatial parameters. 
In addition, the correlations between the spatial parameters and $\mathrm{R}^{2}$ of the regression model are greater in the Near Zone $(30 \mathrm{~m})$ than in the All Zone $(60 \mathrm{~m})$, whereas the correlations between the spatial parameters and slopes of the regression lines are greater in the All Zone $(60 \mathrm{~m})$ than in the Near Zone $(30 \mathrm{~m})$. Hence, the spatial parameter in the Near Zone $(30 \mathrm{~m})$ affects the smoothness of the sound attenuation curve, whereas the spatial parameter in the All Zone $(60 \mathrm{~m})$ affects the slope of the sound attenuation curve.

Table 1 Correlation coefficient between the spatial parameters and regression models

\begin{tabular}{|c|c|c|c|c|c|}
\hline & $\begin{array}{l}\mathrm{R}^{2} \text { of the } \\
\text { linear } \\
\text { regression } \\
\text { model }\end{array}$ & $\begin{array}{l}\text { Slope of the } \\
\text { sound } \\
\text { attenuation } \\
\text { curve }\end{array}$ & $\mathrm{RTSTD}_{10-60}$ & $\begin{array}{c}\text { Mean RT30 } \\
\text { in area of } \\
10-60 \mathrm{~m}\end{array}$ & $\begin{array}{l}\text { Mean EDT } \\
\text { in the } \\
\text { stable area }\end{array}$ \\
\hline$W$ & .142 & $.794^{* *}$ & $.433^{* *}$ & .076 & $.645^{* *}$ \\
\hline$W_{\text {vehicle }}$ & .105 & $.738^{* *}$ & $.377^{* *}$ & .046 & $.715^{* *}$ \\
\hline$W_{\text {side }}$ & .141 & $.703^{* *}$ & $.388^{* *}$ & .083 & $.467^{* *}$ \\
\hline$H_{\text {All }}$ & $.204^{*}$ & $-.487^{* *}$ & $-.224^{* *}$ & $.466^{* *}$ & $-.225^{* *}$ \\
\hline$H_{N e a r}$ & $.222^{* *}$ & $-.585^{* *}$ & $-.378^{* *}$ & $.390^{* *}$ & $-.354^{* *}$ \\
\hline$C_{\text {sAll }}$ & .067 & $-.864^{* *}$ & $-.427^{* *}$ & $.345^{* *}$ & $-.631^{* *}$ \\
\hline$C_{s N e a r}$ & .019 & .230 & $-.518^{* *}$ & $.233^{* *}$ & $-.691^{* *}$ \\
\hline$C_{p A l l}$ & $.229^{* *}$ & $-.822^{* *}$ & $-.407^{* *}$ & $.399^{* *}$ & $-.462^{* *}$ \\
\hline$C_{p N e a r}$ & $.273^{* *}$ & $-.816^{* *}$ & $-.569^{* *}$ & .153 & $-.558^{* *}$ \\
\hline$\sigma\left(H_{A l l}\right)$ & -.121 & $.406^{*}$ & .115 & -.046 & -.049 \\
\hline$\sigma\left(H_{N e a r}\right)$ & $-.198^{*}$ & .315 & .120 & .013 & .056 \\
\hline$\sigma\left(C_{p A l l}\right)$ & $-.465^{* *}$ & $.530^{* *}$ & $.409^{* *}$ & -.016 & $-.451^{* *}$ \\
\hline$\sigma\left(C_{\text {pNear }}\right)$ & $-.468^{* *}$ & .257 & $.374^{* *}$ & .062 & $-.352^{* *}$ \\
\hline
\end{tabular}

The marks * and ** indicate significant correlations: * represents $p \leq 0.05$, and $* *$ represents $p \leq 0.01$

\subsubsection{Prediction model}

Based on the above results, the regression analysis is made using a stepwise linear regression analysis method with the slope of the sound attenuation curve as the dependent variable and the spatial parameter as the independent variable. As shown in Table 2, a multiple regression model of the sound attenuation curve slope is established after three 
iterations. The adjustment $\mathrm{R}^{2}$ of the regression model is 0.910 , which indicates that the explanatory degree of the slope of the sound attenuation curve is $91.0 \%$ in this multiple regression model. The Estimate Std. Error is much smaller than the dependent variable Std. Deviation, which indicates that the regression model has a good fitting. Referring to the Durbin-Watson Table $(T=144, K=3, \alpha=0.05)$, the Durbin-Watson value lies in the indecisive range, which indicates that there is no statistical evidence that the error terms are positively auto-correlated. The significant coefficients and $T$ values indicate that the model complies with the statistical requirements. All VIF values are below 10, which indicates a stable model with no colinearity among the independent variables. Therefore, the regression model formula can be established:

$m_{r}=19.137-2.261 C_{s A l l}-3.003 C_{p N e a r}+0.045 \mathrm{~W}_{\text {vehicle }}$

where $m_{r}$ is the slope of the sound attenuation curve.

According to the regression model, the correlations of $C_{p N e a r}$ and $C_{s A l l}$ on the slope of the regression model are negative and strong, and the correlation of $W_{\text {vehicle }}$ on the slope of the regression model is positive and weak. Therefore, the sound attenuation trend could be improved by reducing $C_{s A l l}, C_{p N e a r}$ or increasing $\mathrm{W}_{\text {vehicle. }}$ In addition, in terms of quantitative guidance of urban road planning and sound environment optimisation, if $C_{s A l l}$ decreases $14.7 \%$, or $C_{p N e a r}$ decreases $11.1 \%$, or $W_{\text {vehicle }}$ increases $7.38 \mathrm{~m}$, the sound attenuation will increase only by $0.1 \mathrm{~dB}$ with doubling sound propagation distance.

\subsection{RT30}

\subsubsection{Basic features of RT30}

Figure 6(a) shows the distributions of RT30 along the direction of sound propagation. In the mean curve, the mean RT30 linearly increases for $0.35 \mathrm{~s}$ in the first propagation distance of 0 to $10 \mathrm{~m}$. This trend slows down in the propagation distance of 10 to $20 \mathrm{~m}$. Finally, the mean RT30 remains at $2 \mathrm{~s}$ in the propagation distance of 20 to $60 \mathrm{~m}$. In the percentile curves L5 and L95, RT30 of each measuring point is mainly distributed between $1.0 \mathrm{~s}$ and $3.0 \mathrm{~s}$.
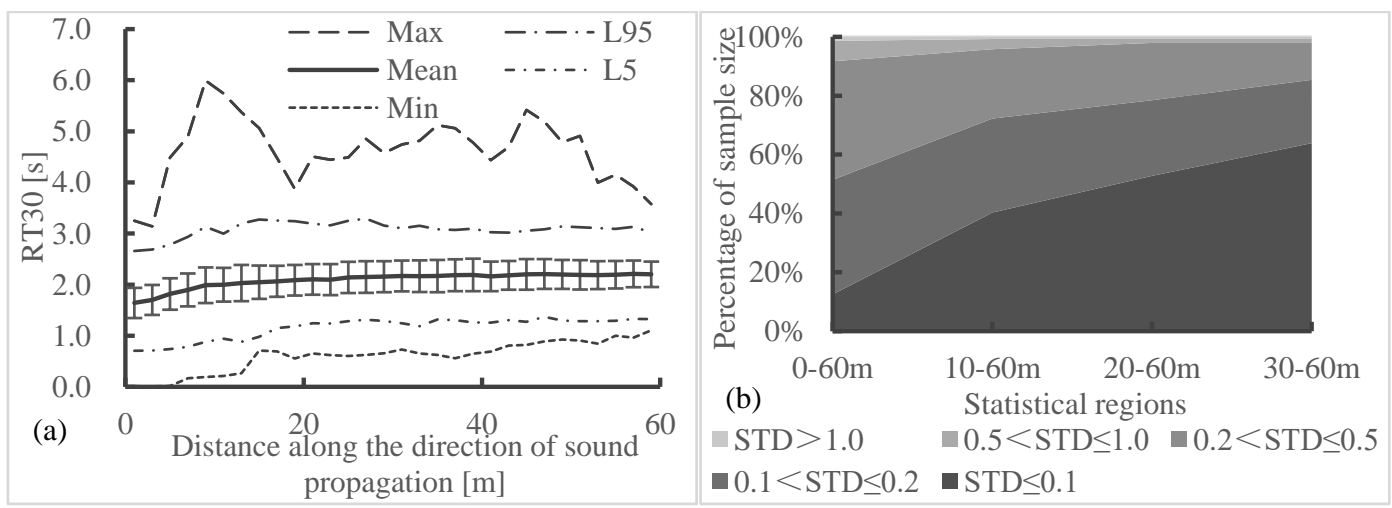

Figure 6 RT30 distribution and Standard deviation. (a) RT30 distribution along the propagation directions; (b) RT30 Standard deviation in different statistical regions. 
Table 2 Multiple regression models

\begin{tabular}{|c|c|c|c|c|c|c|c|c|c|}
\hline $\begin{array}{l}\text { Dependent } \\
\text { variable }\end{array}$ & $\begin{array}{c}\text { Adjusted } \\
\mathrm{R}^{2}\end{array}$ & $\begin{array}{l}\text { Estimate Std. Error / } \\
\text { Dependent variable } \\
\text { Std. Deviation }\end{array}$ & $\begin{array}{l}\text { Durbin- } \\
\text { Watson }\end{array}$ & $\begin{array}{c}\text { Independent } \\
\text { variable }\end{array}$ & $\begin{array}{l}\text { Unstandardized } \\
\text { Coefficients }\end{array}$ & $\begin{array}{l}\text { Standardized } \\
\text { Coefficients }\end{array}$ & $\mathrm{T}$ & Sig. & VIF \\
\hline \multirow{4}{*}{$\begin{array}{l}\text { Slope of } \\
\text { sound } \\
\text { attenuation } \\
\text { curve }\end{array}$} & \multirow{4}{*}{0.910} & \multirow{4}{*}{$0.421 / 1.405$} & \multirow{4}{*}{1.748} & (Constant) & 19.137 & & 37.398 & 0.000 & \\
\hline & & & & $C_{\text {sAll }}$ & -2.261 & -0.326 & -3.435 & 0.002 & 3.022 \\
\hline & & & & $C_{p N e a r}$ & -3.003 & -0.494 & -6.994 & 0.000 & 1.671 \\
\hline & & & & $W_{\text {vehicle }}$ & 0.045 & 0.011 & 3.965 & 0.002 & 2.147 \\
\hline \multirow{4}{*}{$\begin{array}{l}\text { Mean } \\
\text { RT30 in } \\
\text { the area of } \\
10-60 \mathrm{~m}\end{array}$} & \multirow{4}{*}{0.950} & \multirow{4}{*}{$0.498 / 0.551$} & \multirow{4}{*}{1.683} & $H_{A l l}$ & 0.037 & 0.322 & 6.437 & 0.000 & 7.143 \\
\hline & & & & $W_{\text {side }}$ & 0.052 & 0.309 & 10.554 & 0.000 & 2.451 \\
\hline & & & & $C_{\text {sNear }}$ & 1.709 & 0.326 & 7.470 & 0.000 & 5.441 \\
\hline & & & & $\sigma\left(C_{\text {pNear }}\right)$ & 0.136 & 0.140 & 5.484 & 0.000 & 1.862 \\
\hline \multirow{3}{*}{$\begin{array}{l}\text { Mean EDT } \\
\text { in the } \\
\text { stable area }\end{array}$} & \multirow{3}{*}{0.927} & \multirow{3}{*}{$0.465 / 0.750$} & \multirow{3}{*}{1.813} & $W_{\text {vehicle }}$ & 0.052 & 0.722 & 13.224 & 0.000 & 3.018 \\
\hline & & & & $\sigma\left(C_{p A l l}\right)$ & -0.198 & -0.281 & -5.513 & 0.000 & 2.627 \\
\hline & & & & $C_{\text {sNear }}$ & 1.998 & 0.529 & 10.834 & 0.000 & 2.411 \\
\hline
\end{tabular}


In this study, the standard deviation (STD) was used to determine the balance of RT30 in different regions. Figure 6(b) shows the comparison of RT30 STD in four statistical regions, which are as follows: all 30 receivers are in the sound propagation distance of 0 to $60 \mathrm{~m}, 25$ receivers are in the sound propagation distance of 10 to $60 \mathrm{~m}, 20$ receivers are in the sound propagation distance of 20 to $60 \mathrm{~m}$, and 15 receivers are in the sound propagation distance from 30 to $60 \mathrm{~m}$. Figure 6(b) shows that for the statistical region of 0 to $60 \mathrm{~m}$, the percentage of sample size with STD $\leq 0.20$ is $51.39 \%$; for the statistical region of 30 to $60 \mathrm{~m}$, the percentage of sample size with STD $\leq 0.20$ is $85.42 \%$. Thus, in the street, RT30 tends to be stable with the increasing propagation distance.

\subsubsection{Analysis of factors}

In general, the variation of RT30 is small along the propagation direction, and RT30 tends to be stable with the increasing propagation distance. However, in a portion of samples, the variations of RT30 remain large along the propagation direction. Table 1 shows the correlation coefficient between the spatial parameters and RT30 STD in the sound propagation distance of 10 to $60 \mathrm{~m}$ (RTSTD10-60). There are significant correlations between RTSTD $10-60$ and the remaining spatial parameters, except $\sigma(H)$, where $W, W_{\text {vehicle }}$, $W_{\text {side }}$ and $\sigma\left(C_{p}\right)$, have positive correlations, and $H, C_{s}$, and $C_{p}$ have negative correlations. Therefore, it can be considered that a wider street with lower façade height, smaller plan enclosure degree, more uneven distribution of façades, and smaller cross-sectional enclosure degree will have a smaller variation of RT30 in the sound propagation distance of 10 to $60 \mathrm{~m}$. It is notable that only $C_{s N e a r}$ and $C_{p N e a r}$ have greater correlation coefficients $(\mathrm{r}>0.5)$ among all spatial parameters. Therefore, $C_{s N e a r}$ and $C_{p N e a r}$ significantly affect the stability of RT30 in the sound propagation distance of 10-60 m.

Table 1 also shows the correlation coefficient between the spatial parameters and the mean RT30 in the sound propagation distance of 10 to $60 \mathrm{~m}\left(\overline{R T 30_{10-60}}\right)$. It can be observed that $H, C_{s}$, and $C_{p}$ have significant positive correlations with $\overline{R T 30_{10-60}}$, where spatial parameters from All Zone are better than that from Near Zone. $\sigma(H), \sigma\left(C_{p}\right)$ and all $W$ parameters have no significant correlations with $\overline{R T 30_{10-60}}$. This means that in urban streets, the higher the building façade, the greater enclosure degree of plan and crosssection, the larger the $\overline{R T 30_{10-60}}$ will be.

\subsubsection{Prediction model}

All samples are selected as the study objects. Using the stepwise linear regression analysis method, a multiple regression model is established with a high adjustment $\mathrm{R}^{2}$ value at 0.950 , as shown in Table 2. Similarly, with the sound attenuation regression model, all regression analysis parameters, including Durbin-Watson value $(\mathrm{T}=144, \mathrm{~K}=4, \alpha=0.05)$, Estimate Std. Error, Dependent variable Std. Deviation, significant coefficients, T values and VIF values, indicate that the model complies with the statistical requirements. Therefore, the regression formula can be established below:

$$
\overline{R T 30_{10-60}}=0.037 H_{\text {All }}+0.052 W_{\text {side }}+1.709 C_{\text {sNear }}+0.136 \sigma\left(C_{\text {pNear }}\right)
$$


where $\overline{R T 30_{10-60}}$ is the mean RT30 in the sound propagation distance of 10 to $60 \mathrm{~m}$.

According to this regression model, although the correlations of $H_{\text {All }}, W_{\text {side, }} C_{s N e a r}$ and $\sigma\left(C_{\text {pNear }}\right)$ with $\overline{R T 30_{10-60}}$ are all positive, the correlations of the first three parameters are equally stronger than that of the last one. That means $\overline{R T 30_{10-60}}$ could be decreased by reducing $H_{\text {All }}, W_{\text {side, }}, C_{\text {sNear }}$ and $\sigma\left(C_{p N e a r}\right)$. What is notable is that the correlations of $\sigma\left(C_{\text {pNear }}\right)$ with $\overline{R T 30_{10-60}}$ indicates that a more evenly distribution of building gaps in the Near Zone will lead to a greater $\overline{R T 30_{10-60}}$. Also, in terms of quantitative guidance of urban road planning and sound environment optimisation, if $H_{\text {All }}$ decreases $2.70 \mathrm{~m}$, or $W_{\text {side }}$ decreases $1.92 \mathrm{~m}$, or $C_{\text {sNear }}$ decreases $5.9 \%$, or $\sigma\left(C_{\text {pNear }}\right)$ decreases 0.74 , the mean RT30 in the sound propagation distance from 10 to $60 \mathrm{~m}$ will decrease by $0.1 \mathrm{~s}$.

\subsection{EDT}

\subsubsection{Basic features of EDT}

Figure 7 (a) shows the distributions of EDT along the direction of sound propagation. The mean EDT increases from 0 to $1.2 \mathrm{~s}$ in the first propagation distance of 0 to $30 \mathrm{~m}$ and increases from 1.2 to $1.5 \mathrm{~s}$ in the propagation distance of 30 to $60 \mathrm{~m}$. The standard deviation rapidly increases in the propagation distance of 0 to $30 \mathrm{~m}$ and remains at $0.9 \mathrm{~s}$ in the remaining propagation distance. Regarding the percentile curves L5 and L95, in the propagation distance of 0 to $20 \mathrm{~m}$, the main distribution range of EDT is 0 to $1.0 \mathrm{~s}$; in the propagation distance of 20 to $30 \mathrm{~m}$, the main distribution range of EDT rapidly expands from 0 to $1.0 \mathrm{~s}$ to 0 to $3.0 \mathrm{~s}$; in the propagation distance of 30 to $60 \mathrm{~m}$, the main distribution range of EDT remains at 0 to $3.0 \mathrm{~s}$.
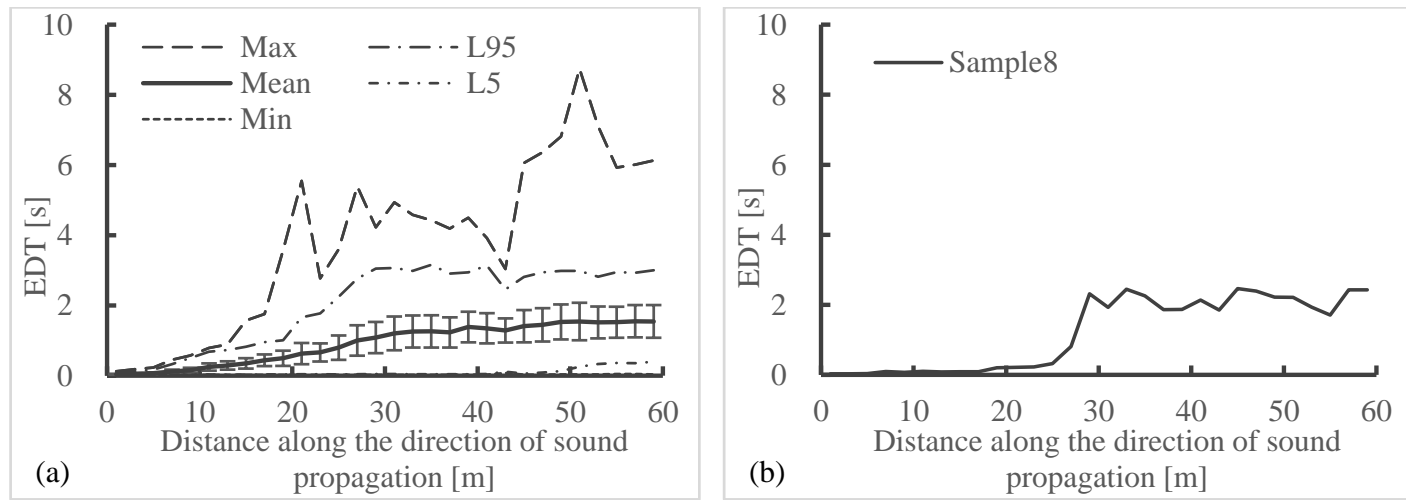

Figure 7 EDT distribution along the propagation directions. (a) Distribution; (b) A typical EDT distribution curve.

\subsubsection{Analysis of factors}

Previous studies (Kang, 2000 ; Lee and Kang, 2015) have found that the EDT rapidly increases in the near field and becomes relatively steady in the far field. Figure 7 
(b) shows the EDT distribution curve of sample 8. As a typical EDT distribution curve, more than $70 \%$ of the samples show the same characteristics. That is, in the first area, the EDT value is notably small and nearly equals zero. With a sudden increase, the EDT maintains at a relatively stable value in the second area (stable area) of 0 to $3.0 \mathrm{~s}$.

Table 1 shows the correlation coefficient between the spatial parameters and the mean EDT (in the stable area). The spatial parameters with a strong correlation ( $>0.6)$ with the mean EDT are $W, W_{\text {vehicle }}$ and $C_{s}$, where $W$ and $W_{\text {vehicle }}$ have a positive correlation and $C_{s}$ has a negative correlation.

\subsubsection{Prediction model}

As shown in Table 2, the multiple regression model of the mean EDT in the stable area was established with the mean EDT in the stable area as the dependent variable and the spatial parameters as the independent variable. The stepwise linear regression analysis method is used. A high $\mathrm{R}^{2}$ and all reliable regression analysis parameters indicate that the model complies with the statistical requirements. Therefore, the regression model formula can be established:

$\overline{E D T}=0.052 W_{\text {vehicle }}-0.198 \sigma\left(C_{p A l l}\right)+1.998 C_{\text {sNear }}$

where $\overline{E D T}$ is the mean EDT in the stable area.

Referred to Standardized Coefficients, $W_{\text {vehicle }}$ have the strongest positive correlation with the mean EDT, and $\sigma\left(C_{p A l l}\right)$ have a weaker negative correlation with the mean EDT.

According to this regression model, the correlations of $W_{\text {vehicle, and } C_{s N e a r} \text { with }}$ $\overline{E D T}$ are both strong and positive, and that of $\sigma\left(C_{p A l l}\right)$ is weaker and negative. $\overline{E D T}$ could be decreased by reducing $W_{\text {vehicle }}$ and $C_{s N e a r}$, and increasing $\sigma\left(C_{p A l l}\right)$. Differencing with $\overline{R T 30_{10-60}}$, a more evenly distribution of building gaps in the All Zone will lead to a smaller $\overline{E D T}$. Again, in terms of quantitative guidance of urban road planning and sound environment optimisation, if $W_{\text {vehicle }}$ decreases $1.92 \mathrm{~m}$, or $C_{s N e a r}$ increases $5.0 \%$, or $\sigma\left(C_{p \text { All }}\right)$ decreases 0.51 , the mean EDT in the stable area will decrease by $0.1 \mathrm{~s}$.

\section{Conclusions}

In this study, a large-scale survey was performed on the sound propagation in the urban streets of Harbin. The results indicate that different spatial parameters affect different acoustic indices differently. Therefore, the corresponding spatial parameters could be used for the specific acoustic index design in urban street. Overall, with the new and reliable street spatial parameters, and the large amount of street samples, the sound propagation prediction models obtained by this study could be applicable in actual urban streets.

The sound attenuation is linearly correlated $\left(R_{M I N}^{2}=0.977, p=0.000\right)$ with the logarithm of the distance from the source to the receivers in almost all streets. The sound attenuation curve is smoother with the higher plan enclosure degree, more even façade 
distribution, more uniform façade heights, and higher mean façade of the Near Zone. The trend of sound attenuation has stronger negative linear correlations with the Crosssectional enclosure degree and Plan enclosure degree and positive linear correlations with the Street width, Vehicle lane width and Sidewalk width. Thus, the trend of sound attenuation is smaller with the higher plan enclosure degree, higher façade, and narrower street. According to the prediction model of the slope of the sound attenuation curve, the Cross-sectional enclosure degree of All Zone, Plan enclosure degrees of the Near Zone, and Vehicle lane width play the most important roles. In addition, the spatial parameter in the Near Zone $(30 \mathrm{~m})$ affects the smoothness of the sound attenuation curve, whereas the spatial parameter in the All Zone $(60 \mathrm{~m})$ affects the slope of the sound attenuation curve.

Unlike the sound attenuation, RT30 tends to be stable with the increase in propagation distance and is primarily distributed between $1.0 \mathrm{~s}$ and $3.0 \mathrm{~s}$. A street with relatively lower façades, narrower sidewalks width, smaller cross-sectional enclosure degree in the Near Zone and more unevenly distribution of building gaps in the Near Zone will have a smaller mean RT30 in the sound propagation distance from 10 to $60 \mathrm{~m}$.

The typical EDT distribution curve was divided into two areas. In the first area, the EDT value is notably small, which rapidly increases to a relatively stable value in the stable area. The mean EDT in the stable area increases with the wider vehicle lane, higher façade, higher plan enclosure degree, and more even façade distribution. According to the prediction model, the mean EDT in the stable area will increase by $0.1 \mathrm{~s}$ when the Vehicle lane width increases by $1.9 \mathrm{~m}$, the Cross-sectional enclosure degree of the Near Zone increases by 0.05 , or the Standard deviations of Plan enclosure degree of All Zone decreases by 0.5 .

\section{Acknowledgment}

This research is funded by the National Natural Science Foundation of China (51378139).

\section{References}

Barceló MA, Varga D, Tobias A, et al. (2016) Long term effects of traffic noise on mortality in the city of Barcelona, 2004-2007. Environmental Research 147: 193206.

Bullen R and Fricke F. (1976) Sound propagation in a street. Journal of Sound and Vibration 46: 33-42.

Christensen CL. (2007) Industrial, Auditorium and Combined Editions. Version 9.0 User Manual. Odeon Room Acoustics Program. Kgs. Lyngby: Odeon A/S.

Durbin J and Watson GS. (1951) Testing for serial correlation in least squares regression. II. Biometrika 38: 159-178.

Echevarria Sanchez GM, Van Renterghem T, Thomas P, et al. (2016) The effect of street canyon design on traffic noise exposure along roads. Building and Environment 97: 96-110.

Efroymson M. (1960) Multiple regression analysis. Mathematical methods for digital computers 1: 191-203. 
Hansen MH, Hurwitz WN and Madow WG. (1953) Sample survey methods and theory, : Wiley New York.

Heutschi K. (1995a) Computer model for the calculation of the increase of traffic noise emission due to buildings along a street. Acustica 81: 26-35.

Heutschi K. (1995b) A simple method to evaluate the increase of traffic noise emission level due to buildings, for a long straight street. Applied Acoustics 44: 259-274.

Hocking RR. (1976) A Biometrics invited paper. The analysis and selection of variables in linear regression. Biometrics 32: 1-49.

Hothersall DC, Horoshenkov KV and Mercy SE. (1996) Numerical modelling of the sound field near a tall building with balconies near a road. Journal of Sound and Vibration 198: 507-515.

Ismail MR and Oldham DJ. (2005) A scale model investigation of sound reflection from building façades. Applied Acoustics 66: 123-147.

Jang HS, Kim HJ and Jeon JY. (2015) Scale-model method for measuring noise reduction in residential buildings by vegetation. Building and Environment 86: 8188.

Kang J. (1996) MODELLING OF TRAIN NOISE IN UNDERGROUND STATIONS. Journal of Sound and Vibration 195: 241-255.

Kang J. (2000) Sound propagation in street canyons: Comparison between diffusely and geometrically reflecting boundaries. The Journal of the Acoustical Society of America 107: 1394-1404.

Kang J. (2001) Sound propagation in interconnected urban streets: a parametric study. Environment and Planning B: Planning and design 28: 281-294.

Kang J. (2002) Numerical modelling of the sound fields in urban streets with diffusely reflecting boundaries. Journal of Sound and Vibration 258: 793-813.

Kang J, Tsou J-Y and Lam S. (2001) Sound propagation in urban streets: comparison between UK and Hong Kong. Proceedings of the Eighth International Congress on Sound and Vibration, Hong Kong, 2 July 2001, pp. 1241-1248.

Kim M-J, Yang H-S and Kang J. (2014) A case study on controlling sound fields in a courtyard by landscape designs. Landscape and Urban Planning 123: 10-20.

Kutner MH, Nachtsheim C and Neter J. (2004) Applied linear regression models, New York: McGraw-Hill/Irwin.

Lee K and Davies H. (1975) Nomogram for estimating noise propagation in urban areas. The Journal of the Acoustical Society of America 57: 1477-1480.

Lee PJ and Kang J. (2015) Effect of Height-To-Width Ratio on the Sound Propagation in Urban Streets. Acta Acustica united with Acustica 101: 73-87.

Liu D and Li G. (2010) From aesthetic fashion to regional rationality - inspirations from evolutionary Harbin architectural creation in new century. Architectural Journal 7: 14-20.

Liu J. (2012) Study on Harbin urban spatial structure (In Chinese). The Journal of Harbin CommitteeSchool of the CCP 1: 68-74.

MOHURD and AQSIQ. (2011) Code for Design of Urban Road Traffic Facility (GB 50688-2011), Beijing: China Planning Press.

Oldham D and Radwan M. (1994) Sound propagation in city streets. Building Acoustics 1: $65-88$. 
Onaga H and Rindel JH. (2007) Acoustic characteristics of urban streets in relation to scattering caused by building façades. Applied Acoustics 68: 310-325.

Pan W, Yu Y and Wan N. (2011) Harbin Central District Integrationand Adjustment Strategies. Planners 27: 34-38.

Picaut J, Le Pollès T, L'Hermite P, et al. (2005) Experimental study of sound propagation in a street. Applied Acoustics 66: 149-173.

Picaut J and Simon L. (2001) A scale model experiment for the study of sound propagation in urban areas. Applied Acoustics 62: 327-340.

Radwan MM and Oldham DJ. (1987) The prediction of noise from urban traffic under interrupted flow conditions. Applied Acoustics 21: 163-185.

Schendera CF. (2014) Regressionsanalyse mit SPSS. Germany: De Gruyter Oldenbourg

Sun Y. (2005) Analysis on Traffic Adaptability of Harbin Urban Road Network. MEng Thesis, Harbin Institute of Technology, China.

Van Renterghem T, Salomons E and Botteldooren D. (2006) Parameter study of sound propagation between city canyons with a coupled FDTD-PE model. Applied Acoustics 67: 487-510.

Wiener FM, Malme CI and Gogos CM. (1965) Sound propagation in urban areas. The Journal of the Acoustical Society of America 37: 738-747. 